\title{
KARAKTERISASI GRINDING BALLS PRODUKSI CV BAJA ELLIPS
}

\author{
Arianto Leman Soemowidagdo ${ }^{1}$ Tiwan $^{2}$, Nurdjito ${ }^{3}$ \\ 1,2,3 Program Studi Teknik Mesin UNY \\ Email: arianto_ls@uny.ac.id
}

\begin{abstract}
This research is aimed to study the characteristics of cast grinding balls produced by CV Baja Ellips Ceper, Klaten. The samples were taken from three tapping. One group was quenched in water while the other was not. The studied characteristics comprised of chemical composition, microstructure, hardness and wear. The result shows that the grinding balls have the chemical composition of medium-strength cast iron. However, the microstructure shows cementite and pearlite that indicates the structure of a white cast iron. The hardness of quenched and unquenched grinding balls are $60 \mathrm{HRC}$ and $57 \mathrm{HRC}$, respectively. The hardness is consistent from the edges to the middle of the grinding balls. The specific wear of quenched grinding balls and unquenched grinding balls is $3.32963 \times 10^{-06} \mathrm{~mm}^{2} / \mathrm{kg}$ and $5.032 \times 10^{-06} \mathrm{~mm}^{2} / \mathrm{kg}$, respectively.
\end{abstract}

Keywords: grinding balls characteristics, materials characterization, grinding mill, casting process

\begin{abstract}
ABSTRAK
Penelitian ini bertujuan untuk mengetahui karakteristik grinding balls produksi CV Baja Ellips Ceper Klaten yang dibuat dengan menggunakan proses pengecoran. Sampel grinding balls diambil dari tiga kali tapping yang berbeda. Satu kelompok dicelup dingin dalam air dan yang tidak dicelup dingin. Karakterisasi yang dilakukan meliputi komposisi kimia, struktur mikro, kekerasan dan keausan. Hasil penelitian menunjukkan bahwa komposisi kimia dari bola penggiling termasuk dalam kelas besi tuang kekuatan sedang. Struktur mikro yang tampak adalah sementit dan perlit yang menunjukkan struktur besi tuang putih. Kekerasan grinding balls yang dicelup dingin adalah 60 HRC sedangkan yang tanpa dicelup dingin sebesar 57 HRC. Kekerasan grinding balls konsisten dari bagian tepi sampai bagian tengah. Keausan spesifik grinding balls yang dicelup dingin dan tanpa dicelup dingin berturut-turut $3,32963 \times 10^{-06} \mathrm{~mm}^{2} / \mathrm{kg}$ dan $5,032 \times 10^{-06} \mathrm{~mm}^{2} / \mathrm{kg}$.
\end{abstract}

Kata kunci: Karakteristik grinding balls, karakterisasi material, mesin penggiling, proses pengecoran

\section{PENDAHULUAN}

Salah satu bahan dasar pembuat bata ringan dan semen adalah pasir silika yang banyak sekali terdapat di Rembang (https://silicasumursongo.wordpress.com/2013/ 02/). Cadangan pasir silika di daerah tersebut dapat dimanfaatkan hingga ratusan tahun ke depan. Pasir silika harus digerus terlebih dahulu menjadi butiran halus menggunakan gyratory jaw crusher atau impact crusher. Grinding balls (bola-bola penggiling) atau kadang disebut juga ball mill adalah salah satu komponen penting pada crusher.

Grinding balls dibuat dari baja atau besi yang disyaratkan berkarakteristik keras, tahan aus, tangguh (tidak mudah pecah) serta tahan korosi. Saat ini, kebutuhan grinding balls baru sebagian kecil saja mampu dipenuhi oleh produsen dalam negeri. Sebagian besar kebutuhan grinding balls masih diimpor karena belum banyak produsen di Indonesia yang mampu membuat grinding balls sesuai spesifikasi teknis yang disyaratkan. Ironis, karena di Indonesia banyak terdapat sentrasentra pengecoran logam yang mestinya mampu memenuhi kebutuhan grinding balls.

Banyak usaha telah dilakukan untuk menigkatkan kualitas grinding balls agar memenuhi spesifikasi teknis yang disyaratkan. Didik dan Amelia (2000) menelaah temperatur optimal yang mempengaruhi kekerasan grinding ball yang dibuat dengan cara hot rolling. Sedangkan, Kartikasari, dkk. (2007) melakukan 
karakterisasi terhadap ball mill impor yang digunakan di pabrik semen. Tujuannya agar dapat dibuat rekayasa untuk membuat ball mill sesuai kebutuhan. Pada tahun yang sama, Setiyana dan Revelino (2007) mengkarakterisasi ball mill pada proses pembuatan semen. Selanjutnya, karakteristik ball mill yang dibuat dari skrap baja karbon dan paduan krom terhadap kekerasan, keausan dan ketangguhan impak juga telah diselidiki Sumpena (2013). Lebih jauh, Sumpena (2014) memberi perlakuan quenching terhadap ball mill. Namun, karakterisasi, perlakuan panas atau penambahan paduan ini tidak diterapkan pada grinding balls atau ball mill produksi industri lokal. Pada penelitian-penelitian sebelumnya, grinding balls dibuat dengan cara hot rolling dan pengecoran menggunakan tanur induksi. Faktanya sebagian besar industri pembuat grinding balls merupakan Industri Kecil Menengah (IKM) yang mengandalkan tanur kupola.

CV Baja Ellips merupakan IKM pengecoran logam di Ceper, Klaten yang salah satu produk andalannya adalah grinding balls. Proses produksinya mengandalkan tanur kupola dengan kapasitas produksi rata-rata 100 ton per bulan. Pembuatan grinding balls di IKM ini telah menerapkan proses quenching dengan teknik sederhana namun efektif. Bagaimanapun, acapkali grinding balls produksi CV Baja Ellips secara teknis tidak lolos quality control yang diterapkan oleh industri bata ringan maupun semen.

Proses peleburan pada tanur kupola dilakukan secara kontinyu. Pada saat baja di bagian bawah tanur telah cair, lubang cerat dibuka untuk mengeluarkan baja cair. Isi tanur kupola akan berkurang seiring dengan keluarnya besi cair. Oleh karenanya tanur kupola diisi lagi dari atas dengan isian: batu bara atau kokas, baja skrap, batu kapur dan logam paduan lainnya. Pengisian dan pengeluaran ini berlangsung kontinyu. Tanur ini cocok untuk produksi masal dengan kapasitas besar, namun sangat sulit untuk menjaga konsistensi dan keseragaman produk.

Penelitian ini merupakan langkah awal untuk meningkatkan kualitas grinding balls produksi CV Baja Ellips, Ceper, Klaten. Karakterisasi terhadap grinding balls produksi CV Baja Ellips diperlukan untuk analsis langkah selanjutnya. Kurang sempurnanya proses pembuatan grinding balls dapat ditelaah dari karakterisasi ini yang selanjutnya dapat digunakan sebagai acuan untuk perbaikan kualitas produk.

\section{METODE}

Grinding balls produksi CV Baja Ellips diambil dari satu hari proses kontinyu, sehingga pengaruh komposisi lapisan bata tahan api dapat diasumsikan sama. Sampel grinding balls yang diambil adalah permintaan satu konsumen sehingga komposisi dan bobot bahan baku pada tanur kupola saat peleburan diasumsikan sama meski proses peleburan kontinyu dan pemasukan bahan baku dilakukan berulang kali. Sampel diambil secara acak dari 3 kali tapping hasil tanur kupola. Hal ini dilakukan untuk melihat konsistensi hasil peleburan tanur kupola.

Penuangan dilakukan pada cetakan logam yang dinding luarnya dialiri air bertekanan untuk menjaga suhu cetakan. Penuangan dilakukan secara manual sehingga logam yang dituang terlebih dahulu akan membeku lebih awal. Grinding balls yang telah di tuang dapat langsung dicelup dingin ke dalam air secara bersamaan atau sama sekali tidak dicelup dingin sesuai kebutuhan. Sampel dibagi menjadi dua kelompok yaitu dicelup dingin dan tidak.

Kedua kelompok sampel kemudian diamati struktur mikronya serta diuji komposisi kimia, kekerasan dan keausan. Struktur mikro di amati pada mikroskop optik olympus dengan eye piece sedang kekerasan rockwell C (HRC) di uji pada Mitutoyo Whizard 500 hardness tester. Uji kekerasan dilakukan dari sisi tepi grinding balls sampai ke sisi tepi lagi. Interval titik pengujian 2 mm. Keausan di uji pada Ogoshi High Speed Universal Wear Testing Machine, Type OAT-U di Laboratorium Bahan JTMI FT UGM. Sedang uji komposisi kimia dilakukan di PT Itokoh Ceperindo, Klaten. Semua data pengujian dicatat, diambil reratanya kemudian 
dibandingkan. Hasil data tersebut kemudian dianalisis secara deskriptif dan diambil kesimpulan.

Ketangguhan grinding balls tidak diselidiki. Dimensi sampel yang berukuran kecil tidak dapat dibuat benda uji impact. Gambar 1 memperlihatkan sampel grinding balls yang diteliti.

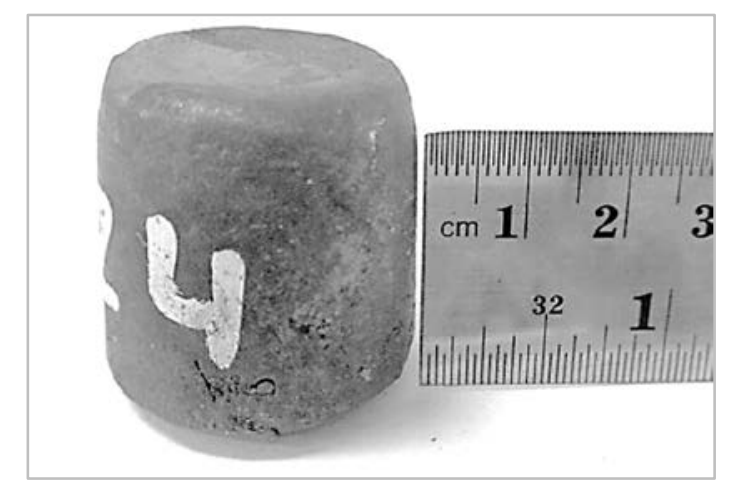

Gambar 1. Sampel grinding balls produksi CV Baja Ellips

\section{HASIL DAN PEMBAHASAN}

Komposisi kimia grinding balls diperoleh melalui uji komposisi. Hasil uji komposisi kimia yang disajikan pada Tabel 1 menunjukkan bahwa komposisi bahan grinding balls produksi CV Baja Ellips cukup homogen. Produk CV Baja Ellips ini sesuai dengan komposisi besi tuang kekuatan sedang. Secara teoritis besi tuang kekuatan sedang memiliki komposisi kimia sebagai berikut: 2,8-3,0 \%C, 1,5-1,7 \%Si; 0,8$1,0 \% \mathrm{Mn} ; \leq 0,3 \% \mathrm{P} ; \leq 0,12 \% \mathrm{~S}$ (Hendro, 2010).

Pengamatan lebih jauh tampak bahwa komposisi kimia grinding balls produksi CV Baja Ellips cukup konsisten. Hal ini mengingat cukup sulit menjaga konsistensi komposisi kimia pada proses peleburan logam menggunakan dapur kupola. Konsistensi kompisisi kimia ini tidak terlepas dari konsistensi penggunaan sumber bahan baku, kecermatan penimbangan bahan baku serta proses peleburannya. CV Baja Ellips cukup baik dalam menjaga konsistensi produknya.

Tabel 1. Komposisi kimia grinding balls produksi CV. Baja Ellips.

\begin{tabular}{ccccccccccc}
\hline \multicolumn{2}{c}{ Unsur } & $\mathrm{Fe}$ & $\mathrm{S}$ & $\mathrm{C}$ & $\mathrm{Ni}$ & $\mathrm{Nb}$ & $\mathrm{Si}$ & $\mathrm{Cr}$ & $\mathrm{V}$ & $\mathrm{Mn}$ \\
\hline $\begin{array}{c}\text { Komposisi } \\
(\%)\end{array}$ & Tapping 1 & 89,9529 & 0,4446 & 3,3482 & 2,1433 & 0,0007 & 2,2362 & 0,7669 & 0,015 & 0,7505 \\
\hline \multicolumn{2}{c}{ Tapping 3 } & 89,0191 & 0,5384 & 4,3009 & 1,8662 & 0,0007 & 2,0532 & 0,6581 & 0,013 & 1,1590 \\
\hline \multicolumn{2}{c}{ Unsur } & & & & & & & & & \\
\hline $\begin{array}{c}\text { Komposisi } \\
(\%)\end{array}$ & Tapping 1 & 0,0013 & 0,0024 & 0,0430 & 0,2093 & 0,0112 & 0,0115 & 0,0110 & 0,0023 & 0,0406 \\
\hline
\end{tabular}

Pengujian berikutnya yang dilakukan adalah analisis struktur mikro. Struktur mikro grinding balls yang dicelup dingin adalah sama dengan yang tidak dicelup dingin seperti ditunjukkan pada Gambar 2. Tampak bahwa grinding balls menunjukkan struktur besi tuang putih. Fasa yang tampak dalam gambar adalah perlit (gelap) dan sementit (terang).

Struktur mikro ini sama untuk tapping 1, 2 dan 3. Ini membuktikan bahwa grinding balls produk CV Baja Ellips konsisten. Secara teoritis, kompisisi kimia besi tuang kelabu dan besi tuang putih adalah sama. Perbedaannya adalah besi tuang putih diperoleh melalui pendinginan cepat. Proses pembuatan grinding balls di CV Baja Ellips adalah menuangkan cairan besi ke cetakan logam. Dinding luar cetakan logam tersebut dialiri air bertekanan tinggi. Sebenarnya teknik ini dilakukan untuk menjaga agar suhu cetakan logam tetap stabil. Teknik ini memungkinkan grinding balls dibuat dengan laju produksi tinggi sehingga mampu merespon permintaan konsumen. Namun, teknik ini juga membuat laju pendinginan 
grinding balls relatif cukup cepat jika dibandingkan dengan penuangan pada cetakan pasir.
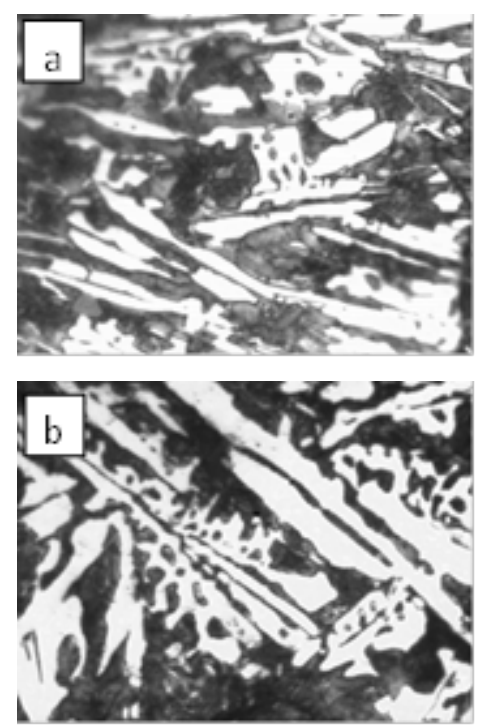

Gambar 2. Struktur mikro grinding balls produksi CV Baja Ellips. (a) di celup air; (b) tidak di celup air

Hasil pengamatan terhadap struktur mikro ini menjelaskan bahwa pencelupan dingin setelah penuangan secara signifikan tidak berpengaruh terhadap karakteristik grinding balls. Kondisi ini terjadi karena laju pendinginan grinding balls yang dicelup dingin hampir sama dengan grinding balls yang tidak di celup. Hal ini membuktikan bahwa teknik penuangan pada cetakan logam yang dilakukan oleh CV Baja Ellips dapat meningkatkan laju produksi dengan konsistensi produk yang cukup bagus.

Pengujian selanjutnya adalah uji kekerasan. Hasil uji kekerasan yang tampak Gambar 3 dan 4 menunjukkan bahwa kekerasan grinding balls produk CV Baja Elips seragam dari tepi sampai tengah. Hal ini tampak pada produk yang dicelup dingin maupun tidak. Ukuran produk yang dikarakterisasi pada penelitian ini tidak terlalu besar sehingga laju pendinginan yang cukup seragam pada grinding balls produksi CV Baja Ellips.

Rata-rata kekerasan grinding balls yang dicelup dingin yang diperlihatkan pada Gambar 3 tampak tidak terlalu mengumpul. Kondisi ini disebabkan oleh metode pendinginan yang dilakukan. Pada proses pencelupan dingin, sesaat setelah grinding balls mulai membeku, langsung di celup ke dalam sebuah bak berisi air yang tidak mengalir atau bersirkulasi. Hal ini menyebabkan suhu air semakin lama semakin tinggi. Bahkan semakin lama volume air dalam bak semakin lama semakin berkurang karena sedikit demi sedikit air menguap. Lebih jauh, acap kali proses pencelupan dilakukan pada suhu yang kurang tepat. Ini terjadi karena suhu grinding balls tidak dikontrol menggunakan alat ukur presisi saat proses pencelupan. Namun demikian, perbedaan kekerasan yang terjadi pada grinding balls produksi CV Baja Ellips ini tidak terlalu signifikan karena semuanya masih masuk dalam daerah kekerasan besi tuang putih.

Kekerasan grinding balls yang tidak dicelup dingin seperti ditunjukkan pada Gambar 4 tampak mengumpul dengan rata-rata kekerasan 57 HRC. Kondisi ini dapat terjadi karena semua grinding balls mengalami perlakuan yang sama saat dituang ke dalam cetakan logam. Laju pendinginannya dapat dikatakan sama karena dinding luar cetakan logam dialiri air dengan tekanan yang sama. Rata-rata kekerasan grinding balls yang dicelup dingin adalah 60 HRC, sedikit lebih tinggi dari rata-rata kekerasan grinding balls yang tidak dicelup dingin, 57 HRC. Namun demikian, perbedaan rata-rata ini tidak terlalu signifikan seperti tampak pada Gambar 5. Kekerasan ratarata keduanya masih termasuk dalam batasan kekerasan besi tuang putih. 


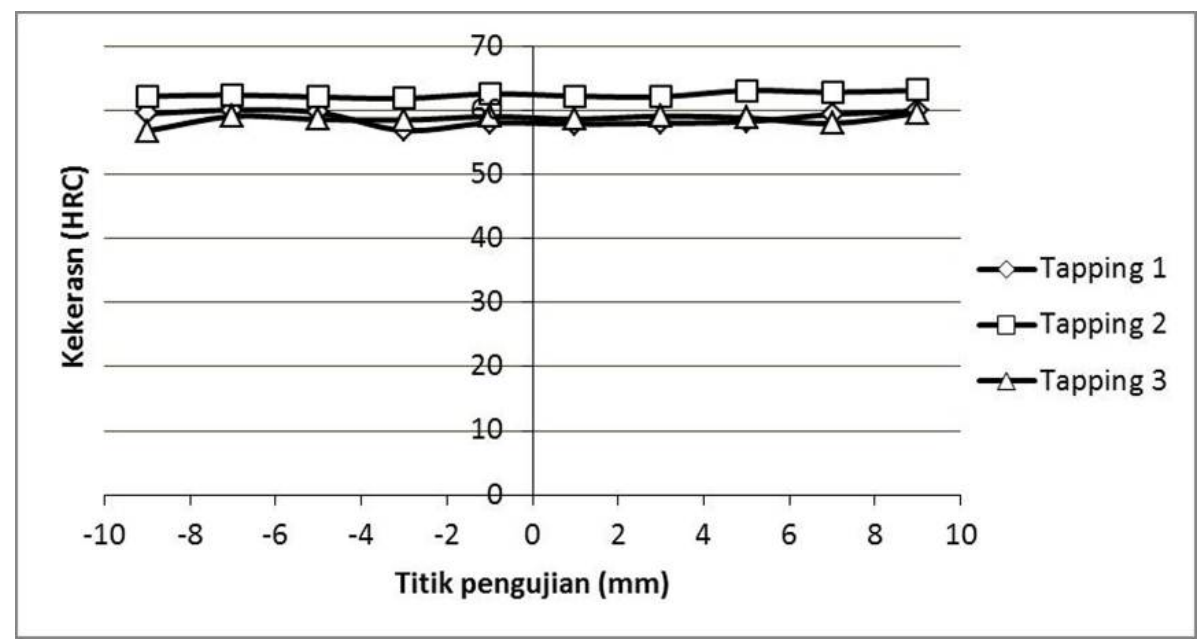

Gambar 3. Kekerasan grinding balls yang dicelup dingin



Gambar 4. Kekerasan grinding balls yang tidak dicelup dingin

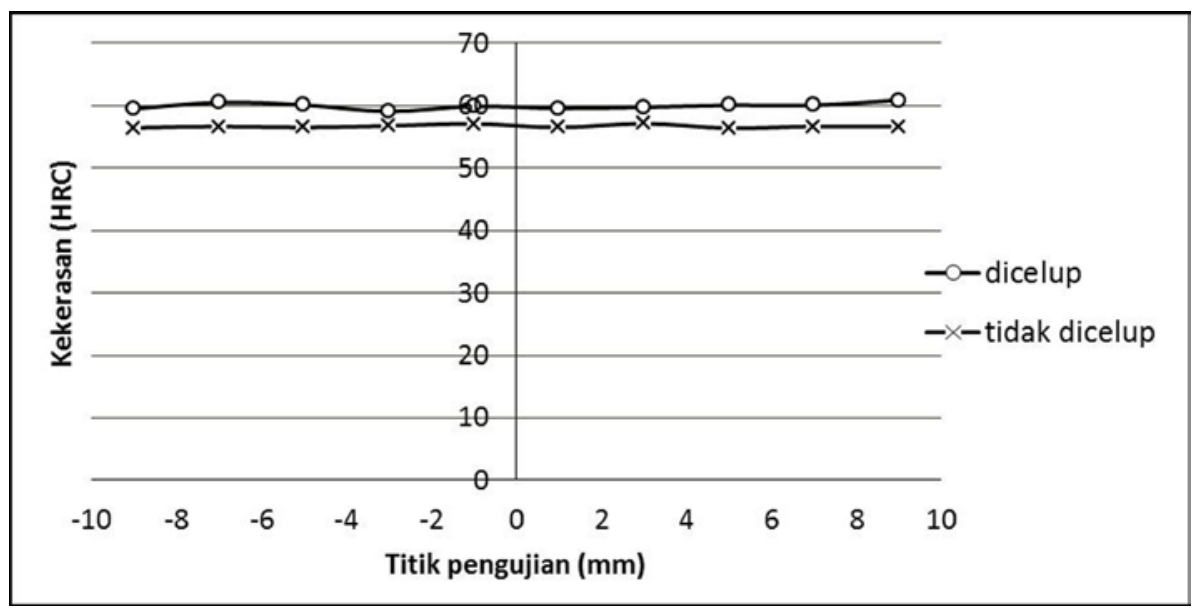

Gambar 5. Kekerasan rata-rata grinding balls yang dicelup dingin dan tidak dicelup dingin

Pengujian berikutnya adalah uji ketahanan aus. Besi tuang putih memiliki kekerasan dan ketahanan aus yang tinggi namun mampu mesin dan kekuatan tariknya rendah.
Besi tuang putih (white cast iron) biasa digunakan dalam pembuatan komponen mesin gerinda, kelengkapan penghancur, komponen dapur pemanas (furnance) dan lain-lain. 
Pengujian keausan dilakukan pada beban $\left(\mathrm{P}_{0}\right)$ 12,72 kg; panjang penggerusan $\left(\mathrm{L}_{0}\right) 400 \mathrm{~m}$; dan lama pengujian 1 menit. Hasil uji keausan disajikan pada Tabel 2.

Tabel 2. Hasil uji keausan

\begin{tabular}{|c|c|c|c|c|c|c|}
\hline Perlakuan & $\begin{array}{c}\text { No } \\
\text { spesimen }\end{array}$ & Uji ke & $\begin{array}{c}\mathrm{b}_{0} \\
(\mathrm{~mm})\end{array}$ & $\begin{array}{c}\mathrm{W}_{\mathrm{S}} \\
\left(\mathrm{mm}^{2} / \mathrm{kg}\right)\end{array}$ & $\begin{array}{c}\mathrm{W}_{\mathrm{S}} \text { rata-rata } \\
\left(\mathrm{mm}^{2} / \mathrm{kg}\right)\end{array}$ & $\begin{array}{c}\mathrm{W}_{\mathrm{S}} \text { rata-rata } \\
\left(\mathrm{mm}^{2} / \mathrm{kg}\right)\end{array}$ \\
\hline \multirow{9}{*}{ 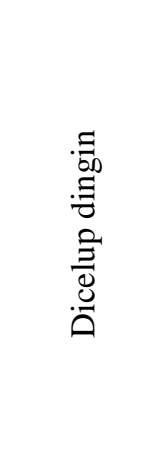 } & \multirow{3}{*}{111} & 1 & 0.90 & 3.528E-06 & \multirow{3}{*}{$3.474 \mathrm{E}-06$} & \multirow{9}{*}{ 3.32963E-06 } \\
\hline & & 2 & 0.93 & 3.964E-06 & & \\
\hline & & 3 & 0.84 & $2.930 \mathrm{E}-06$ & & \\
\hline & \multirow{3}{*}{112} & 1 & 0.80 & $2.560 \mathrm{E}-06$ & \multirow{3}{*}{ 3.092E-06 } & \\
\hline & & 2 & 0.87 & $3.229 \mathrm{E}-06$ & & \\
\hline & & 3 & 0.89 & 3.486E-06 & & \\
\hline & \multirow{3}{*}{121} & 1 & 0.89 & $3.500 \mathrm{E}-06$ & \multirow{3}{*}{ 3.423E-06 } & \\
\hline & & 2 & 0.91 & 3.708E-06 & & \\
\hline & & 3 & 0.85 & 3.061E-06 & & \\
\hline \multirow{9}{*}{ 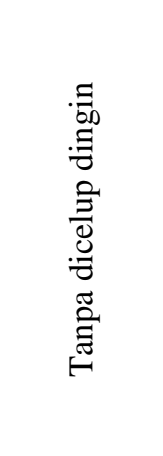 } & \multirow{3}{*}{124} & 1 & 1.05 & $5.696 \mathrm{E}-06$ & \multirow{3}{*}{$5.261 \mathrm{E}-06$} & \multirow{9}{*}{ 5.032E-06 } \\
\hline & & 2 & 1.03 & $5.291 \mathrm{E}-06$ & & \\
\hline & & 3 & 0.99 & 4.797E-06 & & \\
\hline & \multirow{3}{*}{131} & 1 & 0.92 & 3.790E-06 & \multirow{3}{*}{ 6.166E-06 } & \\
\hline & & 2 & 1.16 & 7.642E-06 & & \\
\hline & & 3 & 1.13 & 7.067E-06 & & \\
\hline & \multirow{3}{*}{132} & 1 & 0.97 & 4.512E-06 & \multirow{3}{*}{ 3.668E-06 } & \\
\hline & & 2 & 0.87 & 3.232E-06 & & \\
\hline & & 3 & 0.87 & 3.260E-06 & & \\
\hline
\end{tabular}

Keterangan:

$\mathrm{B}_{0} \quad=$ lebar penggerusan

$\mathrm{W}_{\mathrm{S}}=$ keausan spesifik

Tabel 2 menunjukkan bahwa keausan spesifik grinding balls produksi CV Baja Ellips cukup konsisten meskipun dibuat dari tapping yang berbeda. Ini dibuktikan dengan keuasan spesifik yang mengumpul pada suatu daerah data yang sama. Hal ini berlaku untuk grinding balls yang dicelup dingin maupun tanpa celup dingin.

Perhitungan selanjutnya menunjukkan bahwa grinding balls yang dicelup dingin dan tanpa celup dingin memiliki keausan spesifik berturut-turut 3,32963 x $10^{-06} \mathrm{~mm}^{2} / \mathrm{kg}$ dan 5,032 x $10^{-06} \mathrm{~mm}^{2} / \mathrm{kg}$. Ini berarti grinding balls tanpa celup dingin lebih cepat aus dibanding grinding balls yang dicelup dingin. Namun, perbedaan keausan spesifik grinding balls yang dicelup dingin dengan grinding balls tanpa celup dingin hanya $1,702 \mathrm{x} 10^{-06} \mathrm{~mm}^{2} / \mathrm{kg}$. Hal ini menunjukkan bahwa grinding balls mempunyai umur pakai yang hampir sama.

Bagaimanapun, kekerasan dan keausan spesifik yang tinggi ini belum menjamin ketangguhan dan keuletan grinding balls produksi CV Baja Ellips. Dengan kata lain, kegetasan grinding balls tersebut masih perlu ditelaah lebih lanjut. Kekerasan, keausan, kegetasan dan ketangguhan adalah hal saling terkait. Secara teoritis jika suatu bahan terlalu keras, maka bahan tersebut akan menjadi sangat rapuh. Ini berarti pertikel-pertikel pada bahan tersebut lebih mudah buyar seperti pasir tanpa bahan pengikat.

\section{SIMPULAN}

Hasil karakterisasi grinding balls produksi CV Baja Ellips adalah sebagai berikut: 1) komposisi kimianya grinding balls produksi 
CV Baja Ellips konsisten dan termasuk dalam kelas besi tuang kekuatan sedang; 2) fasa sementit dan perlit pada grinding balls produksi CV Baja memperlihatkan struktur besi tuang putih; 3) kekerasan rata-rata grinding balls produksi CV Baja Ellips yang dicelup dingin 60 HRC dan tanpa dicelup 57 HRC. Kekerasannya konsisten dari bagian tepi sampai bagian tengah dan 4) keausan spesifik grinding balls yang dicelup dingin dan tanpa celup dingin berturutturut adalah $3,32963 \times 10^{-06} \mathrm{~mm}^{2} / \mathrm{kg}$ dan $5,032 \times$ $10^{-06} \mathrm{~mm}^{2} / \mathrm{kg}$.

\section{DAFTAR RUJUKAN}

Bahri. (2013). Sumur Songo Site Area. https://silicasumursongo.wordpress.com /2013/02/ Diakses 28 Maret 2016 jam 08.50 WIB dari

Budi Setiyana dan Revelino Putra Perdana. (2007). Karakterisasi Material Ball Mill Pada Proses Pembuatan Semen dengan Metoda Pengujian Kekerasan, Mikrografi Dan SEM, Rotasi, (9)4, 27 31.
Didik W. dan Amelia. (2000). Penelitian Optimasi Temperatur yang Mempengaruhi Kekerasan pada Pembuatan Grinding Ball dengan Cara Hot Rolling, Jurnal Teknik Mesin. (2)2, 91-96.

Hendro S., (2010). Besi Tuang. https: //tehnikmesinindustri.wordpress.com/20 10/05/26/besi-tuang/. Diakses 21 Oktober 2016 pukul 20.30.

Ratna Kartikasari, R. Soekrisno, M. Noer Ilman, Suharno, Hendri Hestiawan. (2007). Karakterisasi Ball Mill Impor pada Industri Semen di Indonesia, Jurnal Teknik Mesin, (9)1, 18 - 24.

Sumpena. (2013). Karakteristik Ball Mill dari Bahan Baku Scrap Baja Karbon Rendah Paduan Krom Terhadap Kekerasan, Keausan dan Impak. Jurnal Foundry. (3)2, $1-5$.

Sumpena. (2014). Studi Kekuatan Impak dan Struktur Mikro Ball Mill dengan Perlakuan Panas Quenching, Jurnal Foundry. (4)1, 19 - 24. 